\title{
FINTECH IN THE EXCHANGE INDUSTRY: POTENTIAL FOR DISRUPTION?
}

\author{
by \\ MANUELA GERANIO*
}

The recent growth of financial technology ventures involves several types of financial players, including stock exchanges. Many of them are exploring blockchain applications to their multiple business lines, focusing in particular on post trading activities. Potential benefits include the reduction in counterparty risk and post trading costs as well as the increase of liquidity and transparency. At current stage exchanges are mainly exploring the technology looking for proofs of concept, with the exception of some more advanced projects like at Nasdaq and ASX. The mass adoption will require longer efforts and is expected to come in a decade, at least. Fintech developments are receiving strong attention also by regulators and international organizations, given the potential of distributed ledger technology for both competition enhancement and cyber risk reduction. A coordination between market players and regulators is essential to guarantee the effective implementation of new technologies, as their benefits can be delivered only in presence of a common framework and a proper management of risks.

\section{KEY WORDS}

Fintech, Blockchain, Distributed Ledger, Smart Contract, Stock Exchanges

\section{INTRODUCTION}

In recent years global investments in financial technology (Fintech) have boosted, totaling more than 24 billion in 2016. ${ }^{1}$ The "Fintech Revolution" is expected to have a disruptive effect on the financial intermediation

manuela.geranio@unibocconi.it, Adjunct Professor at the Finance Department, Bocconi University, Milan, Italy.

1 KPMG. (2016) The Pulse of Fintech Q4 2016. [online] Available from: https://assets.kpmg. $\mathrm{com} / \mathrm{content} / \mathrm{dam} / \mathrm{kpmg} / \mathrm{xx} / \mathrm{pdf} / 2017 / 02 /$ pulse-of-fintech-q4-2016.pdf

[Accessed 1 March 2017]. 
industry, making finance more cost efficient, consumer friendly and transparent. ${ }^{2}$ The main sectors involved include banking, payment services, insurance, asset management as well as stock exchanges, which are the focus of this contribution.

Fintech developments have attracted potential new players from the tech field (i.e. Google, Amazon, Apple) as well as from the telecommunication (i.e. At\&T, Verizon, Vodafone) which in the next future could fulfill the needs traditionally satisfied by banks and other financial players. As such, also traditional incumbent in the financial industry were forced to heavily invest and start new ventures to assess the potential of the new technologies, in order to defend their own business from incoming competitors.

In the case of stock exchanges, the main Fintech innovation is expected to come from the implementation of the distributed ledger technology or blockchain to run market infrastructures in a more shared and transparent way. According to the World Economic Forum ${ }^{3}$, more than 25 countries are investing in blockchain, filing more than 2,500 patents and investing $\$ 1.3$ billion. ${ }^{4}$ By 2027 , it is expected that $10 \%$ of global GDP will be stored via distributed ledger technology.

In order to defend their business from new potential competitors in the tech and telecommunication industry, all major exchanges have been particularly proactive in exploring blockchain. They are creating start up to investigate the technology (i.e. London Stock Exchange, Chicago Mercantile Exchange, Deutsche Borse) and developing applications to build brand new market infrastructures or partially replace current ones (i.e. Nasdaq and Australian Stock Exchange). ${ }^{5}$

Regulators and international organizations are also paying strong attention to the field, given not only the competition enhancing potential but also the different exposure to cyber risks possibly associated with the distributed ledger technology. Indeed new technologies allow

Economist. (2015) The Fintech Revolution, 9 May.

3 World Economic Forum (2015) The Future of Financial Services. [online] Available from: http://www3.weforum.org/docs/WEF_The_future_of_financial_services.pdf [Accessed 23 September 2016].

4 One of the major developer of the technology is R3, a consortium involving over 80 of the world's largest financial institutions to develop ground-breaking commercial applications for the financial services industry.

5 Rizzo, P. (2016) Ten Stocks and Commodities Exchanges Investigating Blockchain. [online] Available from: https://www.coindesk.com/10-stock-exchanges-blockchain/ [Accessed 23 September 2016]. 
a more transparent and shared accountancy of assets, eliminating the risks associated with the single ledger approach in use nowadays. At the same time unexplored sources of risks could also arise, especially from the cyber environment on which the blockchain is shaped. ${ }^{6}$

The paper is organized as follows: the second paragraph presents the blockchain technology, while the third one focuses on potential applications to the exchange industry. Section four highlights necessary steps for practical implementation, section five describes early projects in place, while section six concludes.

\section{BLOCKCHAIN TECHNOLOGY}

Basically, a blockchain is a public digital register shared by all parties participating to a distributed network. The blockchain records and stores every transactions that occurs in the network, creating an irrevocable and auditable transaction history. Originally developed for Bitcoin (but different from it) such technology has large potential to be implemented on several financial fields, including payment systems and market infrastructures. ${ }^{7}$

Technically the blockchain is a "chain of blocks" in which each block contains information about a certain number of transactions and can be added chronologically to the database (thus forming a "chain") only after it has been validated by the computers on the network ("nodes"), together with a reference to the preceding block. ${ }^{8}$ A copy of the updated blockchain is then stored on all the network members' computers, making it pretty difficult to change or alter any detail in the "transaction history" by any single players. Since the master record is shared by all network members, the blockchain can survive the loss of one node as the registration is always reported on all counterparties shared registry. The blockchain technology offers thus a built-in redundancy that prevents from loss or deliberate alteration of records by one single member of the network. ${ }^{9}$

6 ESMA. (2016) The Distributed Ledger Technology Applied to Securities Markets, Discussion Paper n. 773, June. [online] Available from: https://www.esma.europa.eu/sites/default/files/library/ 2016-773_dp_dlt.pdf (hereinafter referred to as "ESMA, 2016")

7 Stafford P. (2016) Banks struggle to make blockchain fast and secure. Financial Times, 26 September.

8 Fico P. (2016) Virtual Currencies and Blockchains: Potential Impacts on Financial Market Infrastructures and on Corporate Ownership. Available from SSRN: https://ssrn.com/abstract= 2736035

9 Differently, in a database managed by a unique central authority an attack to the latter will automatically damage all the records. 
The "distributed ledger database" enable all the members participating to the network to know almost in real time assets' ownership because each of them has access to the shared registry in which all trades and related ownership changes have been recorded. It is important to highlight that the digital ledger attributes each transaction to a public identifier (i.e. a public key or a code) but they cannot be traced back to a specific person or institution by anyone other than the identifier's owner (by the use of a private key). ${ }^{10}$ Therefore, on the one side transparency is granted to the network participants, as they can always be aware of their counterparties transaction history and holdings, without the need and the costs charged by a third party certificator (such as a bank, an auditor or a central counterparty). At the same time data encryption and the adoption of combined public and private keys allow them to maintain safety and privacy. ${ }^{11}$

Blockchains may be based either on a public or private network. ${ }^{12}$ A public network is an open, peer-to-peer framework, accessible to anyone that wishes to join. As there is no central authority, the network relies on the same participants in order to record and verify transactions according to a certain protocol. Differently, private networks are permissioned networks, so that only trusted parties that have been granted access can join them. In addition, different entities may have varying levels of authority to transact and view data. As such, in private networks a greater control is maintained over users.

Since many of the problems associated with Bitcoins (fraudulent activity, money laundering) depend from the circumstance that the underlying blockchain is a public network, all main implementations of the distributed ledger for the security markets are currently designed on private networks. ${ }^{13}$ Indeed, in a permissioned blockchain model ${ }^{14}$ data validation and access to data can be limited to selected members only (such as traders,

10 Cuccuro P. (2017) Beyond Bitcoin: an Early Overview on Smart Contracts. International Journal of Law and Information Technology, V0, p. 1-17.

11 Not everybody agrees that the privacy enabled by the use of private keys and encryption will be enough (see also Esma, 2016). Indeed in many situations the identity of a market participant, although technically unknown, could be inferred from its trading patterns recorded in the system.

12 FINRA. (2017) Distributed Ledger Technology: Implications of Blockchain for the Securities Industry, January. [online] Available from: http://www.finra.org/industry/blockchain-report

13 For example, the R3 consortium is fully based on a permissioned approach. For further details see https://www.r3.com/ [Accessed 5 March 2017].

14 See also Cuccuro P. (2017) Beyond Bitcoin: an Early Overview on Smart Contracts. International Journal of Law and Information Technology, V0, p. 1-17. 
banks or other qualifies counterparties) in order to minimize naive or fraudulent behaviors. ${ }^{15}$ Some of the advantages of a pure open system have been given up so as to guarantee a safe and orderly cyber environment for financial infrastructures.

A further issue of the blockchain technology is that it facilitates the use of "smart contract", i.e. digital, computable contracts where the performance and enforcement of contractual conditions occur automatically, without the need for human intervention. ${ }^{16}$ Such program strings are self-executing routines that implement a contractual agreement among parties (such as the payment of periodic coupons on a bond or the execution of a derivative contract) without the need of a middleman intervention (such as a bank or a central counterparty). Smart contracts could enhance the enforcement of contract terms and the automation of back office processes, reducing in turn errors and legal disputes and possibly administrative costs.

An example could help to better understand the potential application of the blockchain technology in the financial markets, namely in the security clearing. Figure 1 compares the actual process for clearing financial transactions through a centralized ledger, i.e. the clearing house of an exchange (on the left) with the possible alternative process enabled by a distributed ledger (on the right). Traditionally the clearing house is fundamental to minimize the counterparty risk since once a trade has been agreed between two counterparties the clearing house will act as the buyer to every seller and the seller to every buyer. As such the clearing house centralizes the management of each transaction: registers each trade on a centralized ledger, nets out opposite positions held by traders if any and absorbs related risks. Such function facilitate trading and contribute to liquidity as buyers and sellers do not need to ascertain the credit worthiness of their counterparty, they just need to trust the clearing house (typically owned by the exchange in which the transaction occurred). For its services, the clearing house charge a fee and also requires counterparties to deposit a guarantee (either in cash or in low risk assets) to prove they will honor their obligations. Differently, with the distributed ledger technology (left side of Figure 1) all buyers and sellers can access to the transactions

${ }_{15}$ For example, fraudulent activity could consist in recording fictitious transactions and altering the consensus process (see also ESMA, 2016).

16 Wright, A., De Filippi, P. (2015) Decentralized blockchain technology and the rise of lex cryptographia. Available from SSRN: https://ssrn.com/abstract=2580664 
history, as recorded and updated trade by trade on common register locally held and synchronized among all players in real time. The activity of a central clearing house becomes unnecessary, since each counterparty can ascertain the assets ownership while proper routines can automatically clear out buyers and sellers positions and manage the cash transfers needed to regulate each trade. Since the system works in real time, the post trading duration could reduce form actual standards, thus minimizing also the need for guarantees. Costs and times for post trading activity are therefore expected to reduce substantially, while transparency will increase without affecting execution certainty.

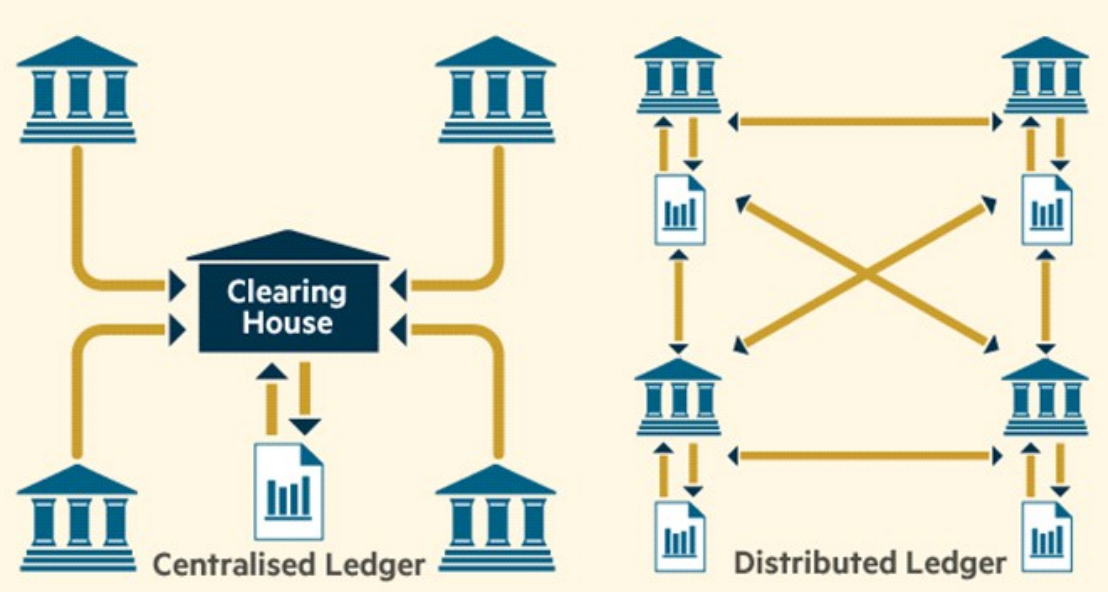

Figure 1: The potential impact of blockchain in the clearing activity ${ }^{17}$

Several benefits are associated with the implementation of the blockchain technology, including disintermediation, higher quality of data, reliability and lack of a central point of attack. Transaction are thus expected to become cheaper, faster but also more reliable and transparent, as processed on an integer peer-to-peer transmission system (see Table 1). At the same time many obstacles and challenges need to be addressed to ensure that all advantages will materialize. From the technological point of view, market applications of the blockchain are still in their infancy and need to be verified and tested for both effectiveness and cyber security. Moreover, a relevant increase in computational capability is needed, as distributed ledgers require substantial amounts of computer power

17 Stafford P. (2016) Banks struggle to make blockchain fast and secure. Financial Times, 26 September. 
to validate transactions. As for the regulatory environment, it just started to cope with the new paradigm and thus it will need time to design an appropriated regulatory framework and integrate it with current laws. The practical adoption will require also a cultural change for users and operators, as they need to familiarize with the new technology, shifting practices to a decentralized network, and to integrate existing systems to the new one. This would require time for learning and also substantial investments in the short run, even if on behalf of future savings.

\begin{tabular}{|c|c|}
\hline Benefits & Challenges \\
\hline $\begin{array}{l}\text { Disintermediation \& trustless exchange } \\
\text { Two parties are able to make an exchange } \\
\text { without the oversight or intermediation } \\
\text { of a third party, strongly reducing or even } \\
\text { eliminating counterparty risk. Users are } \\
\text { in control of all their information } \\
\text { and transactions. }\end{array}$ & $\begin{array}{l}\text { Nascent technology } \\
\text { Resolving challenges such as transaction } \\
\text { speed, the verification process, and data } \\
\text { limits will be crucial in making blockchain } \\
\text { widely applicable. }\end{array}$ \\
\hline $\begin{array}{l}\text { High quality data } \\
\text { Blockchain data is complete, consistent, } \\
\text { timely, accurate, and widely available. }\end{array}$ & $\begin{array}{l}\text { Uncertain regulatory status } \\
\text { Because modern currencies have always } \\
\text { been created and regulated by national } \\
\text { governments, blockchain face a hurdle } \\
\text { in widespread adoption by pre-existing } \\
\text { financial institutions if its government } \\
\text { regulation status remains unsettled. }\end{array}$ \\
\hline $\begin{array}{l}\text { Durability, reliability, and longevity } \\
\text { Due to the decentralized networks, blockchain } \\
\text { does not have a central point of failure and is } \\
\text { better able to withstand malicious attacks. }\end{array}$ & $\begin{array}{l}\text { Large energy consumption } \\
\text { The Bitcoin blockchain network's miners } \\
\text { are attempting } 450 \text { thousand trillion } \\
\text { solutions per second in efforts to validate } \\
\text { transactions, using substantial amounts } \\
\text { of computer power. }\end{array}$ \\
\hline $\begin{array}{l}\text { Process integrity } \\
\text { Users can trust that transactions will be } \\
\text { executed exactly as the protocol commands } \\
\text { removing the need for a trusted third party. }\end{array}$ & $\begin{array}{l}\text { Control, security, and privacy } \\
\text { While solutions exist, including private } \\
\text { or permissioned blockchains and strong } \\
\text { encryption, there are still cyber security } \\
\text { concerns that need to be addressed before } \\
\text { the general public will entrust their } \\
\text { personal data to a blockchain solution. }\end{array}$ \\
\hline $\begin{array}{l}\text { Transparency and immutability } \\
\text { Changes to public blockchains are publicly }\end{array}$ & $\begin{array}{c}\text { Integration concerns } \\
\text { Blockchain applications offer solutions that }\end{array}$ \\
\hline
\end{tabular}




\begin{tabular}{|l|l|}
\hline $\begin{array}{l}\text { viewable by all parties creating transparency, } \\
\text { and all transactions are immutable, meaning } \\
\text { they cannot be altered or deleted. }\end{array}$ & $\begin{array}{l}\text { require significant changes to, or complete } \\
\text { replacement of, existing systems. In order } \\
\text { to make the switch, companies must } \\
\text { strategize the transition. }\end{array}$ \\
\hline \multicolumn{1}{|c|}{ Faster transactions } \\
$\begin{array}{l}\text { Blockchain } \quad \text { transactions can reduce } \\
\text { transaction times to minutes and are } \\
\text { processed 24/7. }\end{array}$ & $\begin{array}{l}\text { Blockchain represents a complete shift } \\
\text { to a decentralized network which requires } \\
\text { the buy-in of its users and operators. }\end{array}$ \\
\hline $\begin{array}{l}\text { By eliminating third party intermediaries } \\
\text { and overhead costs for exchanging assets, } \\
\text { blockchains have the potential to greatly } \\
\text { reduce transaction fees. }\end{array}$ & $\begin{array}{l}\text { Blockchain offers tremendous savings } \\
\text { in transaction costs and time but the high } \\
\text { initial capital costs could be a deterrent. }\end{array}$ \\
\hline
\end{tabular}

Table 1: Main benefits and challenges of blockchain technology ${ }^{18}$

Given its characteristics and products (immateriality of goods traded, electronification of trading, high level of information asymmetries, commercial relations involving often unknown counterparties) the financial sector became one of the first and more natural context for the development and launch of blockchain applications. Early examples involve cryptocurrencies, such as the Bitcoin, which registered mixed results. ${ }^{19}$ More recent projects concern the payment system (such as Ripple, a distributed ledger for international payment which is collecting growing attention by traditional banks), crowdfunding and issuing platforms, and clearing and settlement services providers.

\section{POTENTIAL APPLICATIONS OF BLOCKCHAIN FOR EXCHANGES}

From their foundation in the early 1600s stock exchanges provide a safe and reliable infrastructure that facilitates the transfer of financial resources between savers and borrowers (equities and bonds) as well as the distribution of risk according to preferences (derivatives). The exchange industry expedites such exchanges by reducing information asymmetries and transaction costs. ${ }^{20}$ Moreover, exchanges perform

\footnotetext{
18 Deloitte. (2016) Insights: Blockchain technology. [online] Available from: https://www2.deloitte.com/nl/nl/pages/innovatie/artikelen/blockchain-technology-9benefits-and-7-challenges.html [Accessed 5 March 2017].

19 Swan, M. (2015) Blockchain Ed. O'Reilly.

20 Geranio, M. (2016) The Evolution of the Exchange Industry. Springer.
} 
a regulatory function that guarantees the selection of participants (either listed companies or trading members), the orderly and fair execution of trades and the fulfillment of the related post trading activities (i.e. clearing and settlement operated by a central counterpart).

Blockchain has the potential to further reduce such asymmetries and costs and to replace the central counterpart with a peer-to-peer mechanism. As a consequence, stock exchanges represent one of the major fields that the new technology is expected to impact. Hence it is not a case that all major stock exchanges are already investing to get a better understanding of the blockchain prospective and to implement first applications.

In order to appreciate the possible impact of the distributed ledger technology to an exchange it may be useful to briefly recall the main activities that sequentially compose the life of a security, that is issuing, trading and post trading.

The issuing or primary market phase involve the issue of equities (or bonds), the offer and distribution of securities among the public and the collection of funds from investors. Such activities are completed by the issuing company, usually assisted by banks, legal consultants and providers of administrative services. If the offer is proposed to the large public of investors relevant regulatory and transparency duties have also to be fulfilled, together with obligations of the exchange in which the security is eventually expected to get listed. Indeed, listing activity implies that the entity where the issuer is seeking to be admitted conducts due diligence to assess that the latter is adequately fit and has the attributes investors are looking for.

Trading or secondary market phase involves matching and executing orders received from buyers and sellers either on an official exchange or on an alternative trading system (ATS). Nowadays, trading is fully electronic: orders reach the matching engine of the exchange or ATS via dedicated transmission lines that guarantee maximum speed ${ }^{21}$ (in the order of microseconds) and minimum costs (given the strong competition among official exchanges and ATS). Smart order routers assist traders in deciding which market is best to execute each transaction by collecting and combining information on available order books

${ }^{21}$ More than 5000 trades can occur in a second! 
and automatically send the order. It is estimated ${ }^{22}$ that more than $50 \%$ of trading is nowadays put in place by algo trading, i.e. software programs that do not require human intervention to implement the trading strategy.

Post trading involves several activities, namely clearing, settlement and custody services. In the clearing process, trades are registered and aggregated to establish the respective obligations of the buyer and the seller. Each counterparty's position is netted out by summing up all their buy and sell orders in order to reduce settlement values. Details of the deal such as security identification code, the settlement date and venue, and so forth, are prepared to enable settlement. Clearing houses might also offer other services, such as acting as central counterparty (the buyer to every seller and the seller to every buyer). In doing so, a clearing house replaces the original bilateral contract with two bilateral contracts and guarantees the trade. This aspect takes on special value in the case of derivatives contracts, where no cash flow is due from counterparties before maturity. To cover this risk, the CCP requires traders to post a certain amount of collateral. Settlement is the process by which the legal ownership in the traded asset is transferred and the corresponding payment is made. Giving the existence of network externalities and economies of scale generated by custody activity, ${ }^{23}$ often settlement services are offered jointly by the custodian, using a vertically-integrated structure to perform both activities. Custody is carried out by a depositary, which acts as a "securities bank" that holds physical securities incustody as well as accounts of their ownership. Many depositories offer registration as an additional service (i.e. notary services, proxy voting, information on corporate actions, etc.). At the moment this function is a natural monopoly because regulation requires that the shareholders' register for each security shall be kept at a single institution, which is usually selected by the issuer. ${ }^{24}$ As a consequence, equity custodians are typically based in the same country where the shares are listed. ${ }^{25}$ Overall, post-trade services are highly regulated and major changes in the industry are typically the result of regulator intervention.

\footnotetext{
22 World Federation of Exchanges and Iosco. (2016) Financial Market Infrastructures and Distributed Ledger Technology, August. [online] Available from: https://www.worldexchanges.org

23 Linciano, N., Siciliano, G., and Trovatore, G. (2005) L'industria dei servizi di regolamento delle Operazioni in Titoli Quaderni di Finanza Consob, n. 58, May.

24 Ibid.
} 
Given the above discussed phases that occurs during the life of a security, blockchain applications for exchanges are expected to focus mainly in the post trading field and possibly in the issuance of new securities, while small room is left in the issuing and trading business. Indeed the distributed ledger technology does not allow to reach, at least at the moment, levels of speed and efficiency comparable to those already in place in the trading platforms of exchanges and ATS. In addition, since with the blockchain possession of assets is a pre-requisite for transacting, short selling and margin finance ${ }^{26}$ may be no longer feasible. Also algo-trading and in particular high frequency traders ${ }^{27}$ may find it difficult to develop their strategies, since they will need to wait (for even just a few seconds) for each settlement cycle before they can transact again and this would give rise to a substantial slowdown in their rate of activity. ${ }^{28}$ So far, applications of the distributed ledger including the trading activity have been developed only for less traded securities (such as the SIX platform launched for bonds ${ }^{29}$ ) or new born shares (such as T0 platform in the $\mathrm{US}^{30}$ ).

Differently, post trading is expected to be the most important area for the implementation of fintech in financial market infrastructures. On the one side the new technology will allow a true redesign of current procedures for clearing, settlement and custody, no more anchored to the presence of a central counterpart. On the other side, up to now post trading field has been the least exposed to competition in the exchange industry, as it could benefit from a sort of natural monopoly granted by available technology and regulation. Blockchain could disrupt such monopoly, promoting higher efficiency, shorter duration and cost reduction in post trading processes. ${ }^{31}$

${ }^{25}$ For example the Central Security Depositor (CSD) in Italy is Monte Titoli, in France Euroclear Paris, in Germany Clearstream and in Spain Iberclear. See Chan et al. (2007) The Securities Custody Industry, ECB Occasional Paper Series No. 68, August.

${ }^{26}$ Trading strategies typically employed by hedge funds.

27 High frequency traders use sophisticated algorithms to place orders on several markets at the same time, taking advantage of the extreme speed in order execution.

28 Euroclear and Oliver Wyman (2016) Blockchain in Capital Markets. [online] Available from: http://www.oliverwyman.com/our-expertise/insights/2016/jan/blockchain-in-capitalmarkets.html.

29 SIX. (2017) SIX Securities Services Develops Distributed Ledger-Based Bond Issuing Solution [online] Available from: https://www.six-securities-services.com/en/shared/news/2017/dssnews-170322-distributed-ledger.html [Accessed 31 March 2017].

30 Tzero. (2017) Distributed Ledger Platform for Capital Markets [online] Available from: https://tzero.com/ [Accessed 31 March 2017].

31 Pinna A. and Ruttemberg W. (2016) Distributed ledger technologies in securities post-trading, ECB Occasional Papers, n. 172, April. 
Nowadays the post trade process can be expensive and slow: commonly it takes 2 days to process through a number of intermediaries. Blockchain has the potential to overcome such frictions and provide alternatives to improve management of clearing, settlement and custody (see Figure 2). The adoption of a distributed ledger among market participants could allow a real time clearing for cash transactions, eliminating any manual process and related errors and avoiding the intervention of a central clearing house (and related costs and risks). Indeed, both sides in a transaction will have access to pre-trade transparency details that their counterpart will be able to meet the terms of the deal, and settlement will happen almost instantly. This in turn will eliminate collateral requirements, being the settlement instantaneous (from $\mathrm{T}+2$ to $\mathrm{T}+0$ ). Efficiency will improve, as cash and assets transfers will be recorded on the same ledger. Differently, for derivatives contracts a clearing mechanism will still be needed for the whole length of the contract, but the new technology will allow to optimize netting procedures, reducing counterparty risks, facilitating a more efficient use of collaterals and diminish capital requirements for clients.

Custody services will also be simplified, thanks to higher transparency and process automation made available by the distributed ledger technology. New services, including proxy votes and collateral management, could be offered to clients.

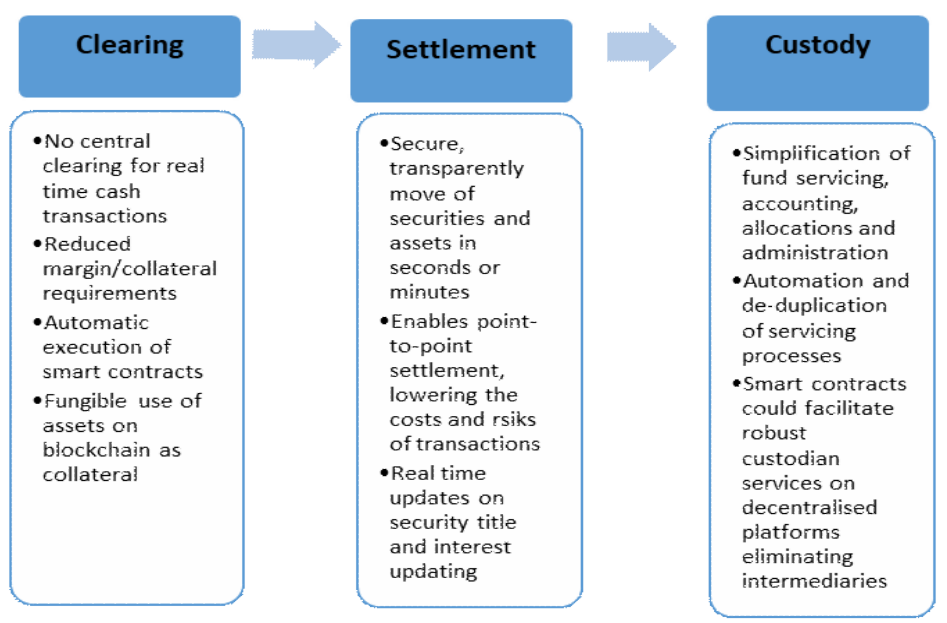

Figure $2^{32}$ : Possible impact of blockchain in post trading activites

32 Santander Innoventures, Oliver Wyman and Anthemis. (2015) The Fintech 2.0 Paper: Rebooting Financial Services. [online] Available from: http://santanderinnoventures.com/ fintech2/ 
Overall, the reduction in time, expenses and counterparty risk associated with blockchain adoption in post trading should result in relevant cost cutting: equity analysts ${ }^{33}$ estimate a $25 \%$ reduction in post trading costs, equivalent to a $7 \%$ decrease in aggregated costs of European exchanges. The Australian Stock Exchange, which is implementing ablockchain solution for their clearing services, estimated it will lead to a $15 \%$ reduction in total exchange costs. In addition, further positive side effects are expected, such as a possible increase in liquidity and transactions motivated by the most effective management of counterparty and market risks. ${ }^{34}$

Higher transparency and auditability of the transaction history is strongly welcomed also by financial regulators and supervisors (ESMA, 2016), which could be granted special access rights to the distributed ledger in order to better exercise their duties. At the same time, the supervision of a network could be more complex than that of central market infrastructures. Moreover, legality and enforceability of the records kept on the blockchain also need to be carefully considered, in the light also of differences in securities and company laws across countries. ${ }^{35}$

As for the issuing activity, the distributed ledger technology could provide new solutions for issuing securities in cryptographically secured digital form, breaking down some of the barriers to entry in financial market for small and medium enterprises (mimicking the impact that crowdfunding had on smaller ventures). This in turn could also facilitate at a second stage the development of a secondary trading market via blockchain, given the limited scope and liquidity of the securities involved. Some examples are already under construction, as reported in the fifth paragraph.

\section{STEPS FOR BLOCKCHAIN DEVELOPMENT IN CAPITAL MARKETS}

The adoption of blockchain in capital markets requires several steps and time. Mass adoption is not expected before 2025, even if it is estimated that in $202710 \%$ of global GDP will be stored on blockchain. ${ }^{36}$

33 JP Morgan Cazenove. (2016) Blockchain: A Revolutionary Technology Too Important to Ignore, Europe Equity Research, 23 May.

34 Ibid.

35 See also ESMA, 2016. 
First, the technology requires further exploration and proofs of concept, with initial investments to explore effective capabilities, scalability, data privacy, performance, identity management and standardization formats. Such phase is already under way, thanks also to the large venture capital involvement in the field, but common procedures still need to be agreed. To guarantee robustness and fair performance very high standards need to be set for the blockchain, together with reliable protocols for integration with existing non-blockchain systems (i.e. risk management platforms). Security issues deserve a special attention, as the risk of intentional security breaches could have unknown consequences. Indeed, if the distributed nature of the ledger does provide some protection (hacking the system would require collusion across the network), it also multiplies the possible points attacked or damaged by an external hacker (i.e. through the execution of an intentionally broken smart contract).

The implementation of smaller scale applications is the second stage. It is needed to allow appreciation of costs, benefits and risks as well as to raise awareness of economic benefits to a wider arena of players. In the case of exchanges, the use of blockchain has already been applied to asset classes with limited trading volume. Projects like Nasdaq Linq and SIX bond market are first examples in this direction. ${ }^{37}$

The third step then will imply the involvement of regulatory authorities, which in many cases already started to investigate the technology to assess its impact also in terms of audit and compliance benefits. Strict collaboration between regulators and the industry will be fundamental to update the legal framework and grant regulatory approval to the new infrastructures. New principles may be needed where blockchain technologies become an integral part of the market infrastructure, and where consensus protocols are run through an international network of participants. Given the global nature of financial services, the agreement will be required across different jurisdictions. A special issue concerns the immutable nature of transactions registered on the blockchain: some technical solution should be identified to allow amendment of wrong registrations caused by errors or fraudulent behaviors, given the wide systemic impact they would otherwise have on all the network participants.

\footnotetext{
${ }^{36}$ See also World Economic Forum (2015) The Future of Financial Services. [online] Available from: http://www3.weforum.org/docs/WEF_The_future_of_financial_services.pdf [Accessed 23 September 2016].

${ }^{37}$ As discussed in paragraph 5.
} 
Once main regulatory issues will have been resolved, the implementation in mainstream asset classes and services will be feasible. At the beginning this will be done in parallel with existing systems (e.g. in clearing), while only after technology has been fully assimilated and tested in practice mass adoption will follow.

Two aspects, out of the numerous operational ones needed to support the effective blockchain implementation, appear particularly relevant. ${ }^{38}$ On the one side a robust cash ledger should be put in place to overcome failures of existing cryptocurrencies (such as the Bitcoin). Indeed, in order to achieve full "Delivery Versus Payment" in settlement (as in actual post trading systems) the blockchain should be able to process central bank money. Some players ${ }^{39}$ are yet investigating in the field in order to either create a digital alternative to fiat currency or find a way to use commercial bank money systems.

On the other side, given the global nature of the financial markets, it will be necessary to establish standards to allow interoperability between different blockchain networks that will be promoted by various market players (stock exchanges, clearing houses, custodians) and for different asset classes (equities, bonds, derivatives). Cooperation among players become thus fundamental to gather full benefits from the new technology implementation. In addition, as distributed ledger technology is expected to expand in progressive steps, interoperability with the existing systems is also important to allow the diffusion of the new protocols without altering market operations. In the long run, interoperability could also foster interconnections among financial markets in different countries, facilitating international trading and diversification not only among most developed financial centers but also in those emerging markets that are willing to adopt the technology and reshape their regulatory framework accordingly.

Given the large impact expected on clearing and settlement, consequences can be expected on the business models used by exchanges to manage the post trading activity. ${ }^{40}$ Currently, some exchanges adopt a vertical model ("silo") $)^{41}$, in which post trading activity are integrated

38 See also ESMA, 2016.

39 Such as the Bank of England.

40 Mainelli M. and Milne A. (2015) The Impact and Potential of Blockchain on the Securities Transaction Lifecycle, Swift Institute Working Paper n. 7.

41 For example Deutsche Borse. 
and performed by the same stock exchange in which trading occurs. Other marketplaces rely on a horizontal model $^{42}$, in which the customer can opt for different providers of postrading services. It is not easy to forecast if the blockchain technology would clearly favor one out of the two models. On the one side the use of a distributed ledger evokes a more open and thus horizontal approach, which would largely benefit from the interoperability among different networks. On the other side, the application of blockchain will imply both high investments and smaller margins for exchanges that provides post trading services. As such incumbents might try to maintain strict control on their permissioned distributed ledgers, at least in the first years, in order to assess the reliability of the network but also to defend their own financial results.

Overall the path to effective implementation of distributed ledger is still long and uncertain. ${ }^{43}$ In addition to main hurdles identified above (technology, regulatory and legal barriers, lack of safe cryptocurrencies, interoperability with existing systems), the presence of vested interests in the preservation of the existing system could delay the adoption of the new technology. Incumbents in the market infrastructure industry (exchanges, central counterparties and depositors, traders and investment banks) could indeed lose their market position and margins from the introduction of the blockchain. The pressure exercised by new entrants in the field is relevant but probably not enough to induce a definite and fast movement of main market players towards the distributed ledger philosophy. A concurrent action by regulators and public authorities could therefore definitely be necessary to support the concrete adoption of the new technology, as it historically happened with other major innovations in the financial field.

\section{RECENT EXPERIENCES}

Despite its quite recent development, first application of blockchain technology started to appear in latest years. Here's in the following some of the main examples.

In late 2015 Nasdaq launched the Linq blockchain technology dedicated to the issue and trading of securities of private companies (a good testing field, since trading is limited and usually occurs between a tight circle

\footnotetext{
${ }^{42}$ For example Euronext.

43 See also World Federation of Exchanges and Iosco (2016).
} 
of investors). The company Chain.com was the first able to use the platform to issue shares to a private investor, documenting a major advance in the application of blockchain technology. Nasdaq enabled the issuer to digitally represent a record of ownership using Nasdaq Linq (a cloud based management tool), while significantly reducing settlement time and eliminating the need for paper stock certificates. A few more companies joined the platform in the following months, and Nasdaq confirmed its strong interest in the distributed ledger technology to be applied also to public markets in the next future. Indeed, at the same time, Nasdaq is developing distributed ledger technology to improve proxy voting, company registration and public-pension registration at the Tallinn Stock Exchange, Estonia's only regulated secondary securities market, as well as the Estonia Central Securities Depository (ECSD).

An alternative example for the issuing field comes from a new entrant in the financial industry: Overstock, an e-commerce corporation that became the first to issue its own corporate bonds on a self-developed blockchain, eliminating the possibility of naked short selling and reducing settlement time to near zero. Six months after the bonds' issue, Overstock earned regulatory approval to issue also equities through its blockchain. In September 2016, the company announced it was partnering with Keystone Capital to work with regulators on further developments for its platform.

In January 2016 the Australian Stock Exchange (ASX) acquired a 10 million stake in Digital Asset Holding, a New York based start up to promote $R \& D$ on blockchain applications. A few months later ASX announced to have completed the first version of a potential distributed ledger-based replacement for its existing settlement system. The process involved working with regulatory bodies in Australia as well as relevant exchange stakeholders. ASX is now weighing how to go about replacing its existing settlement system, known as CHESS, with the new blockchain prototype. ASX expects to conclude investigations and implement the new system by 2018 .

A further example released in 2016 comes from SIX Securities Services (Switzerland's post-trade market infrastructure) that has developed a blockchain powered service covering the full bond trading life cycle from issuance to settlement. The prototype enables the issuing of bonds as smart contracts that specify at what dates coupon payments are made, 
for what amounts and when repayments occur. ${ }^{44}$ The smart contract is connected to the chain where buyers can allocate money to the bond by paying in digitalised currency. SIX Securities Services said the benefits of using blockchain technology include having one source of data stored on the ledger and significant cost reductions from the removal of operations and reconciliation processes.

The central securities depositories of Russia (NSD, National Settlement Depository) also revealed in 2016 to be at work with a tech startup to test the exchange and transfer of blockchain assets. In addition, they signed an agreement with South Africa depository (Strate) to work together on a shared ledger technology project focused on proxy voting.

Blockchain innovations involve also commodities market. In 2016 the Royal Mint, a 1,000-year-old institution owned by HM Treasury, has partnered with with Chicago Mercantile Exchange (CME Group) to build and launch a digitised gold offering called Royal Mint Gold (RMG). The innovative product, launching in 2017, will see The Royal Mint issue RMG as a digital record of ownership for gold stored at its highly-secure on-site bullion vault storage facility. CME Group will develop, implement and operate the product's digital trading platform. Taken together, this new service will provide an easier, cost-effective and cryptographically secure alternative to buying, holding and trading spot gold.

In addition to industry players, concrete signals of interest in the blockchain technology has surged also from regulators and supranational institutions.

Throughout 2016, Central banks became significantly more interested in utilizing blockchain's potential, particularly in the area of settlement. The Bank of England, European Central Bank, Bank of Japan and the US Federal Reserve all announced they were conducting exploratory research into the potential adoption of blockchain, indicating a strong preference to try and foster a culture of digital innovation going forward. ${ }^{45}$

One of the most active regulators in the field has been the Bank of England. First, it has founded FinTech Accelerator in partnership with firms working with new technology to explore how innovations could be used in central banking. In particular, the central bank is testing

\footnotetext{
${ }^{44}$ See also SIX(2017).

45 Bank of America Merrill Lynch. (2016) How Will Blockchain Change European Market Structure? Exchanging Views.
} 
an artificial intelligence system with the Canadian startup MindBridge AI to spot abnormalities in financial transactions and explore the benefit of machine learning technology for analyzing the quality of regulatory data input. It has also partnered with San Francisco-based startup Ripple, to trial a blockchain-based technology that would make cross-border payments and the movement of currencies more immediate. A further long term research programme of the Bank of England concerns the implications of a central bank issuing a digital currency.

G20 countries documents released in 2017 also recognize the potential of Blockchain technologies to build an inclusive global digital economy that is auditable, secure and transparently accountable to the world's citizens. ${ }^{46}$ Hence, G20 countries are expected to take the lead in initiating several concrete steps to support public and private sector blockchain innovations and establish internationally agreed regulatory frameworks to interface with them.

\section{CONCLUSION}

Stock exchanges are currently investing in blockchain technology to maintain their competitive position in the security industry. Main impacts are expected to be on post trading business. Settlement and custody will be the most impacted areas, since the distributed ledger will streamline and shorten the process for holding and exchanging assets. Clearing will also benefit by providing faster margining and risk management, especially for derivatives.

Differently, trading will remain on exchanges and ATS as the actual technology is much faster than blockchain and it is not in the interest of stock exchanges (and of a relevant portion of their clients, such as high frequency traders) to implement the new technology.

Some incumbent players and new entrants in the field are also launching applications in the issuing sector, and some possibility to trade as well, focusing on least served market segments, such as small and medium enterprises, for which extreme speed in transactions is not a relevant issue.

Undoubtedly fintech has a huge potential to rewrite many processes in the financial markets, once technological and regulatory issues will be

46 Maupin J. (2017) The G20 Countries Should Engage with Blockchain Technologies to Build an Inclusive, Transparent, and Accountable Digital Economy for All. G20 Insight. Available from: http://www.g20-insights.org/policy_briefs/g20-countries-engage-blockchain-technologiesbuild-inclusive-transparent-accountable-digital-economy/ 
solved. If it will succeed also in disrupting entry barriers and vested interests of incumbent players is less easy to say, as it will depend upon the efforts put in place by new entrants but also from the sustain that the new technology will receive from regulators and public authorities. First steps taken on this direction authorize an optimistic view.

\section{LIST OF REFERENCES}

[1] Bank of America Merrill Lynch. (2016) How Will Blockchain Change European Market Structure? Exchanging Views, February.

[2] Cuccuro P. (2017) Beyond Bitcoin: an Early Overview on Smart Contracts. International Journal of Law and Information Technology, V0, p. 1-17.

[3] Deloitte. (2016) Insights: Blockchain Technology. [online] Available from: https://www2.deloitte.com/nl/nl/pages/innovatie/artikelen/blockchain-technology-9benefits-and-7-challenges.html [Accessed 5 March 2017].

[4] Dietz M. et al. (2015) Cutting Through the FinTech Noise McKinsey Available from: http://www.mckinsey.com/industries/financial-services/our-insights/cutting-throughthe-noise-around-financial-technology.

[5] Economist. (2015) The Fintech Revolution, 9th May.

[6] ESMA. (2016) The Distributed Ledger Technology Applied to Securities Markets, Discussion Paper n. 773, June. Available from: https://www.esma.europa.eu/sites/default/files/ library/2016-773_dp_dlt.pdf

[7] ESMA. (2017) The Distributed Ledger Technology Applied to Securities Markets. Report, February. Available from: https:/www.esma.europa.eu/sites/default/files/library/dlt_ report_-_esma50-1121423017-285.pdf

[8] Euroclear and Oliver Wyman. (2016) Blockchain in Capital Markets. Available from: http://www.oliverwyman.com/our-expertise/insights/2016/jan/blockchain-in-capitalmarkets.html

[9] Fico P. (2016) Virtual Currencies And Blockchains: Potential Impacts on Financial Market Infrastructures and on Corporate Ownership. Available from SSRN: https://ssrn.com/ abstract $=2736035$

[10] FINRA (2017), Distributed Ledger Technology: Implications of Blockchain for the Securities Industry, January. Available from: http://www.finra.org/industry/blockchain-report

[11] Geranio M. (2016) The Evolution of the Exchange Industry. Springer. 
[12] Chan et al. (2007) The Securities Custody Industry, ECB Occasional Paper Series No. 68, August.

[13] JP Morgan Cazenove. (2016) Blockchain: A Revolutionary Technology Too Important to Ignore, Europe Equity Research, 23 May.

[14] KPMG (2016), The Pulse of Fintech Q4 2016. [Online] Available from: https://assets. kpmg.com/content/dam/kpmg/xx/pdf/2017/02/pulse-of-fintech-q4-2016.pdf [Accessed 1 March 2017].

[15] Lee L. (2016) New Kids on the Blockchain: How Bitcoin's Technology Could Reinvent the Stock Market Hastings Business Law Journal Vol. 12 Winter No. 2.

[16] Linciano N., Siciliano G. and Trovatore G. (2005) L'industria dei servizi di regolamento delle operazioni in titoli Quaderni di Finanza Consob, n. 58, May.

[17] Mainelli M. and Milne A. (2015) The Impact and Potential of Blockchain on the Securities Transaction Lifecycle, Swift Institute Working Paper n. 7.

[18] Malinova K. and Park A. (2016) Market Design with Blockchain Technology. Available from SSRN: https://ssrn.com/abstract=2785626

[19] Maupin J. (2017) The G20 Countries Should Engage With Blockchain Technologies to Build an Inclusive, Transparent, and Accountable Digital Economy for All. G20 Insight. Available from: http://www.g20-insights.org/policy_briefs/g20-countries-engage-blockchaintechnologies-build-inclusive-transparent-accountable-digital-economy

[20] Murck P. (2017) Who Controls the Blockchain? Harvard Business Review, April.

[21] Pinna A. and Ruttemberg W. (2016) Distributed Ledger Technologies in Securities Post-trading, ECB Occasional Papers, n. 172, April.

[22] Rizzo P. (2016) Ten Stocks and Commodities Exchanges Investigating Blockchain. Available from: https://www.coindesk.com/10-stock-exchanges-blockchain/ [Accessed 23 September 2016].

[23] Santander Innoventures, Oliver Wyman and Anthemis (2015), The Fintech 2.0 Paper: Rebooting Financial Services. Available from: http://santanderinnoventures.com/fintech2/

[24] SIX (2017) SIX Securities Services Develops Distributed Ledger-Based Bond Issuing Solution. [online] Available from: https://www.six-securities-services.com/en/shared/news/2017/ dss-news-170322-distributed-ledger.html [Accessed 31 March 2017].

[25] Stafford P. (2016) Banks Struggle to Make Blockchain Fast and Secure, Financial Times, 26 September.

[26] Swan M. (2015) Blockchain Ed. O’Reilly. 
[27] Tzero. (2017) Distributed Ledger Platform for Capital Markets [online] Available from: https://tzero.com/ [Accessed 31 March 2017].

[28] World Economic Forum (2015) The Future of Financial Services, June. Available from: http://www3.weforum.org/docs/WEF_The_future_of_financial_services.pdf [Accessed 23 September 2016].

[29] World Economic Forum (2015) The Future of Fintech: a Paradigm Shift in Small Business Finance, October. Available from: http://www3.weforum.org/docs/IP/2015/FS/GAC15_ The_Future_of_FinTech_Paradigm_Shift_Small_Business_Finance_report_2015.pdf

[30] World Federation of Exchanges and Iosco (2016) Financial Market Infrastructures and Distributed Ledger Technology, August. Available from: https://www.worldexchanges.org

[31] Wright A. De Filippi P. (2015) Decentralized Blockchain Technology and the Rise of Lex Cryptographia. Available from SSRN: https://ssrn.com/abstract=2580664 